\title{
Comment on "The Maximum Possible and the Maximum Expected Earthquake Magnitude for Production-Induced Earthquakes at the Gas Field in Groningen, The Netherlands" by Gert Zöller and Matthias Holschneider
}

\author{
by Julian J. Bommer and Jan van Elk
}

\section{Introduction}

Zöller and Holschneider (2016) propose estimates of the maximum magnitude of induced earthquakes resulting from gas production in the Groningen field in The Netherlands by applying the approach of Zöller and Holschneider (2014) to the earthquake catalog for the Groningen field. We wish neither to make any comment on the analytical approach that the authors propose, nor to comment on their results in this particular application. We do feel obliged to clarify for readers the context of the study by Zöller and Holschneider (2016) in relation to the March 2016 workshop to which they refer. In particular, the sentence in their Introduction stating that "this short note provides the results of those authors" (p. 2917) could be interpreted as implying that their paper presents the results from the workshop. The paper by Zöller and Holschneider (2016) summarizes one of the many inputs that contributed to the workshop, but not the final outcome of the workshop.

\section{Induced Seismic Hazard and Risk in Groningen}

In response to induced earthquakes in the Groningen gas field, the field operator Nederlandse Aardolie Maatschappij (NAM) is leading an extensive data acquisition and modeling effort to quantify the consequent seismic hazard and risk as a basis for decision making regarding appropriate mitigation measures. All the elements of the study are subject to peer review and the results presented in the open literature (e.g., Bourne et al., 2014, 2015; Bommer et al., 2016). Originally, the maximum magnitude $M_{\max }$ for the probabilistic seismichazard analysis (PSHA) conducted for the gas field was set at M 6.5, a value obtained from the seismic moment corresponding to the strain energy associated with the entire field compaction at the end of production life being released in a single seismic event (Bourne et al., 2015). Although the observed strain partitioning factors (i.e., the portion of the total strain that is expressed seismically) are seen to be increasing with compaction, the values remain far below unity and the scenario underlying the $M_{\max }$ estimate of $\mathbf{M} 6.5$ includes several very conservative assumptions. Disaggregation of early hazard and risk estimates showed that the main magnitude contributions were far below this limit and, therefore, that this $M_{\max }$ estimate exerted practically no influence on the results (Bourne et al., 2015). However, subsequent calculations- including risk estimates for low annual exceedance frequencies to match societal safety targets, hazard and risk estimates for longer response periods, and the consideration of liquefaction - prompted consideration of incorporating the epistemic uncertainty in $M_{\max }$, rather than relying on a single conservative estimate.

Because early estimates of $M_{\max }$ for the Groningen field (e.g., van Eck et al., 2006) were repeatedly revised, the estimation of this parameter has become somewhat controversial. Moreover, it was recognized that the estimation of $M_{\max }$ for induced seismicity requires expertise from several disciplines to be integrated while fully accounting for the large uncertainties associated with the estimation of this quantity. In view of these considerations, it was decided to charge a panel of suitably qualified experts with the task of making the assessment of $M_{\max }$ values to be used in the probabilistic seismic-hazard and risk models for Groningen.

\section{The Workshop on Maximum Magnitudes for Groningen}

The objective was to follow the general principles of the Senior Seismic Hazard Analysis Committee (SSHAC; Budnitz et al., 1997) process, which were formulated precisely to facilitate objective multiple-expert hazard assessments in a manner that would most effectively identify and incorporate all epistemic uncertainties. The objective of the SSHAC process has been formulated as capturing the center, the body, and the range (CBR) of technically defensible interpretations (TDIs) of available data, methods, and models (U.S. Nuclear Regulatory Commission [USNRC], 2012), often referred to as the CBR of TDI.

The central role in the SSHAC process is that of a Technical Integration (TI) team, who has the responsibility of making an impartial evaluation of available data, methods, and models, and then integrating these to form a distribution representing the CBR of TDI. Kevin Coppersmith was appointed to lead the TI team, based on his extensive experience in geological hazard assessments following the SSHAC process - having been a member of the original SSHACand, in particular, of addressing the estimation of $M_{\max }$ (e.g., Johnston et al., 1994). Coppersmith then assembled a panel of 


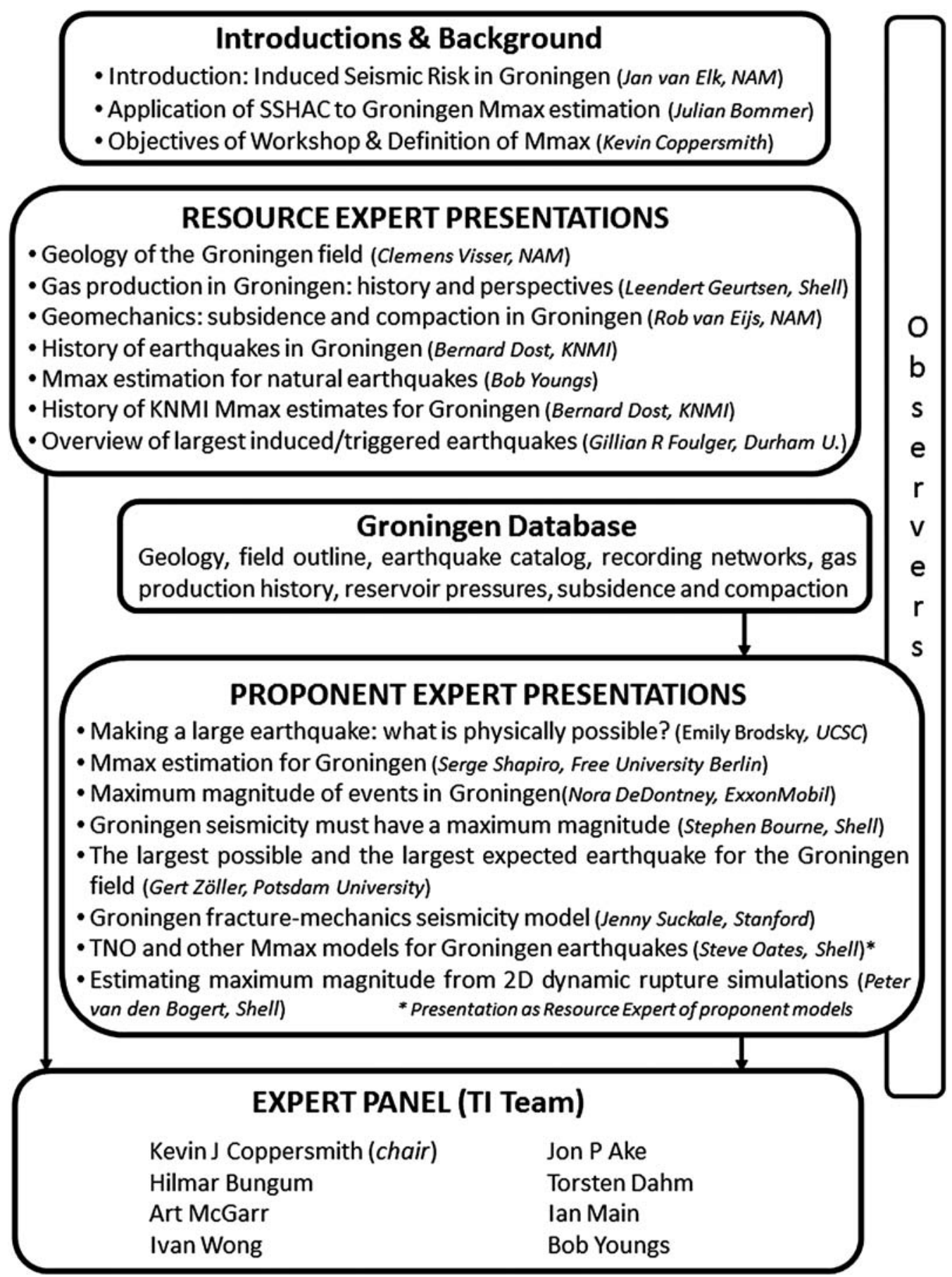

Figure 1. Schematic illustration of the workshop on $M_{\max }$ estimation for the Groningen field; many of the proponent expert presentations had multiple authors but only the presenter is identified. SSHAC, Senior Seismic Hazard Analysis Committee; KNMI, Koninklijk Nederlands Meteorologisch Institut (Royal Dutch Meteorological Institute); TNO, Toegepast Natuurwetenschappelijk Onderzoek (Applied Scientific Research).

internationally recognized experts who collectively brought together a great deal of expertise, both in the estimation of maximum magnitudes for seismic-hazard analysis, and the characterization of induced and triggered earthquakes. The members of the panel are identified in the lowest box in Figure 1.

To assist the panel in their evaluations, a three-day workshop was conducted in Amsterdam in March 2016, in which there were numerous presentations by resource experts, who presented information on the characteristics and history of the Groningen field. Additionally, there were several presentations by proponent experts-all of whom were provided a priori with comprehensive datasets for the field - advocating particular models or values for $M_{\max }$ in Groningen. All of these presentations are summarized in Figure 1, and the complete set of presentations from the workshop is freely available for download as part of the report (NAM, 2016). 


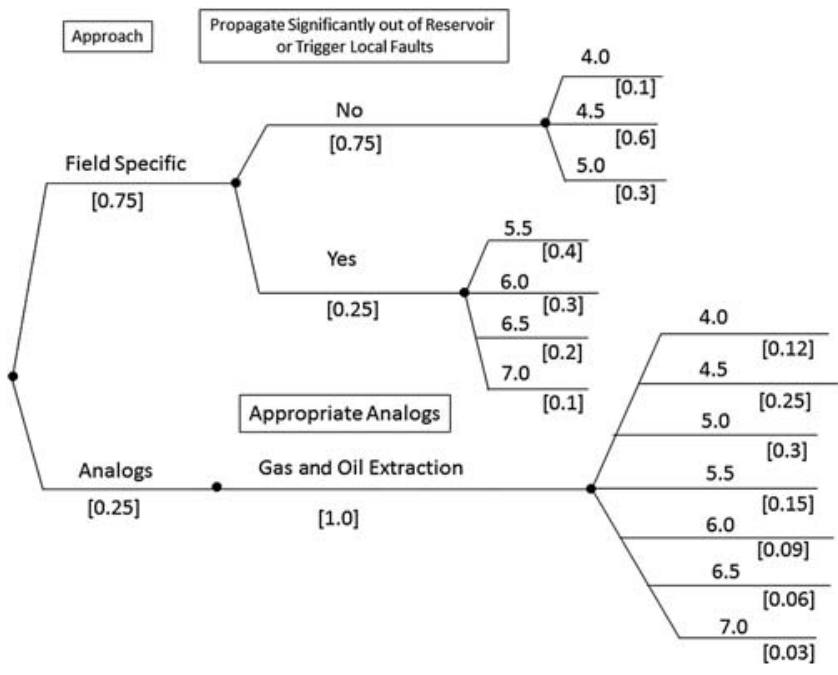

Figure 2. Logic tree developed by the expert panel for $M_{\max }$ in the Groningen field.

\section{Maximum Magnitude of Groningen Earthquakes}

Based on their consideration of all the available information and their interrogation of the proponent experts in the workshop, the expert panel developed a logic tree for $M_{\max }$ in the Groningen field (Fig. 2). The technical justification for the decisions reflected in the logic tree, including their evaluation of each body of evidence and proponent model, is explained in their report, which is included as part of the workshop summary referred to above (NAM, 2016). The logic tree considers the potential for both induced earthquakes associated with ruptures largely contained within the gas reservoir and larger triggered earthquakes associated with ruptures that propagate out of the reservoir and release crustal stresses. The resulting discrete distribution of the logic tree is shown as a histogram of probabilities associated with individual magnitudes in Figure 3.

Figure 3 also shows a cumulative density function of the probabilities constructed by assigning the probability mass in each discrete magnitude bin uniformly over the 0.5 magnitude unit bin width centered on the magnitudes shown in the histogram. Applying the method of Miller and Rice (1983), the equivalent three-point distribution for $M_{\max }$ is given by the following combinations of magnitude and probabilities: M 4.3 (0.430), M 5.2 (0.461), and M 6.6 (0.109). We note that the model advocated by Zöller and Holschneider (2016) is close to the modal value of the distribution, but it is clear that the panel of experts perceive much greater uncertainty in the estimation of $M_{\max }$ than envisaged in the approach of Zöller and Holschneider (2016).

\section{Conclusions}

The work of Zöller and Holschneider (2016) was one of many valuable contributions to the consideration of appropriate $M_{\max }$ values to be used in the ongoing PSHA and risk study for the Groningen field. These authors assert that "the
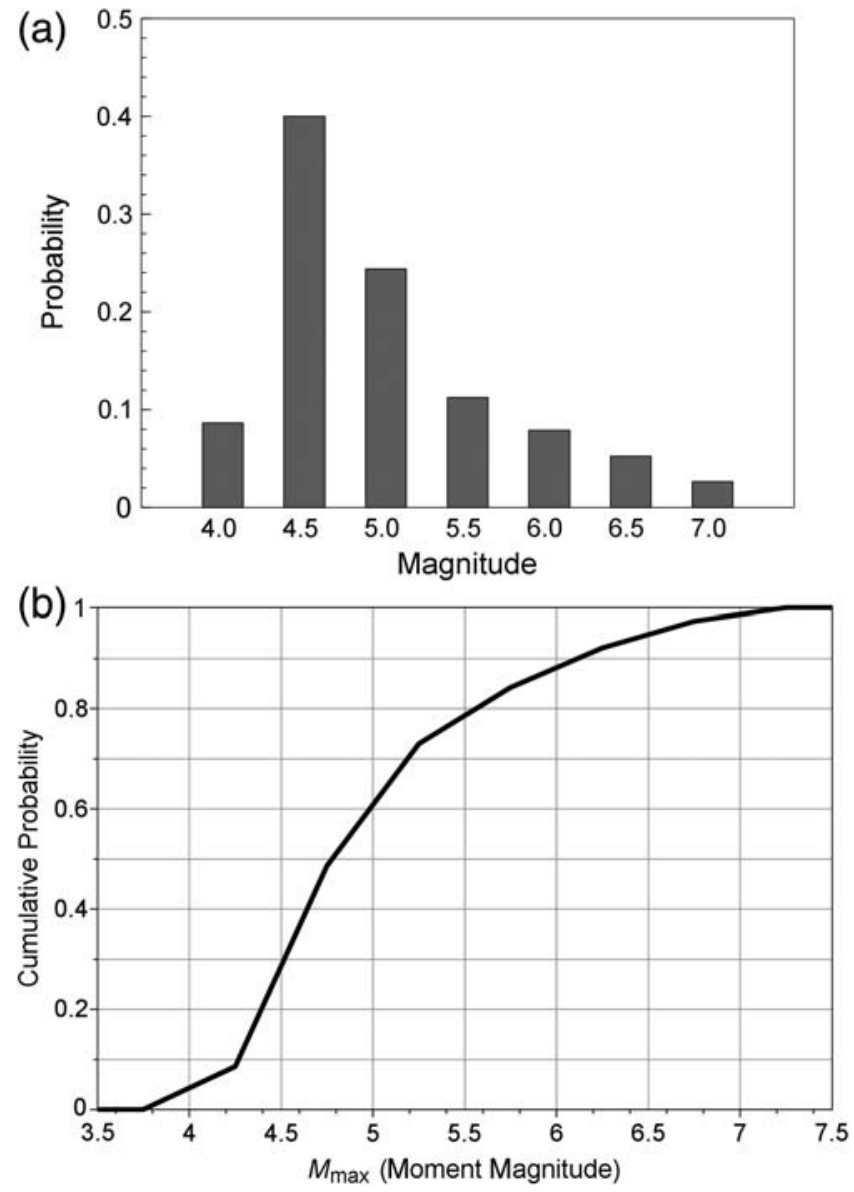

Figure 3. (a) Discrete and (b) continuous probability distributions represented by the $M_{\max }$ logic tree.

fact that the results have a straightforward mathematical interpretation qualifies them for further use in quantitative hazard and risk assessment for the Groningen gas field" (p. 2921). Although the insights and rigor of analysis provided by these renowned mathematicians are appreciated, it is considered more appropriate to adopt the recommendations of a large and highly experienced panel of geologists and seismologists who addressed the issue with impartiality. Moreover, it would be irresponsible to ignore the considerable epistemic uncertainty that these experts identified in the estimation of $M_{\max }$ in developing the seismic risk model for the Groningen field.

The work of the expert panel was limited in time, as a result of regulatory pressures to deliver periodic updates of the hazard and risk estimates, and it is envisaged that work on this important subject will continue. The report of the expert panel included several recommendations for additional studies that could be conducted to refine the $M_{\max }$ model and reduce the associated uncertainties (NAM, 2016).

\section{Data and Resources}

The full report of the workshop on $M_{\max }$ in the Groningen field, including all presentations and the summary report of the expert panel, is freely available for download at 
http://www.nam.nl/feiten-en-cijfers/onderzoeksrapporten .html (last accessed March 2017).

\section{Acknowledgments}

This is an appropriate opportunity to renew our gratitude to the expert panel members who undertook the assessment of $M_{\max }$ for the Groningen field and all of the resource and proponent experts—including G. Zöller and M. Holschneider-who participated in the workshop. A special mention is due to Steve Oates of Shell for assembling the common database provided to the proponent experts and to Rita Etman-Schokker of Nederlandse Aardolie Maatschappij (NAM) for all the logistical support that made the workshop possible. We are also grateful to Associate Editor Ivan Wong and Editor-in-Chief Thomas L. Pratt for useful comments on our original submission.

\section{References}

Bommer, J. J., B. Dost, B. Edwards, P. J. Stafford, J. van Elk, D. Doornhof, and M. Ntinalexis (2016). Developing an application-specific groundmotion model for induced seismicity, Bull. Seismol. Soc. Am. 106, no. $1,158-173$.

Bourne, S. J., S. J. Oates, J. J. Bommer, B. Dost, J. van Elk, and D. Doornhof (2015). A Monte Carlo method for probabilistic hazard assessment of induced seismicity due to conventional natural gas production, Bull. Seismol. Soc. Am. 105, no. 3, 1721-1738.

Bourne, S. J., S. J. Oates, J. van Elk, and D. Doornhof (2014). A seismological model for earthquakes induced by fluid extraction from a subsurface reservoir, J. Geophys. Res. 119, 8991-9015, doi: 10.1002/ 2014JB011663.

Budnitz, R. J., G. Apostolakis, D. M. Boore, L. S. Cluff, K. J. Coppersmith, C. A. Cornell, and P. A. Morris (1997). Recommendations for probabilistic seismic hazard analysis: Guidance on uncertainty and the use of experts, NUREG/CR-6372, Two Volumes, US Nuclear Regulatory Commission, Washington, D.C.

Johnston, A. C., K. J. Coppersmith, L. R. Kanter, and C. A. Cornell (1994). The earthquakes of stable continental regions, five volumes, Final Report for Electric Power Research Institute (EPRI), Palo Alto, California, EPRI TR-102261.
Miller, A. C., and T. R. Rice (1983). Discrete approximations of probability distributions, Manag. Sci. 29, no. 3, 352-362.

Nederlandse Aardolie Maatschappij (NAM) (2016). Groningen Seismic Hazard and Risk Assessment: Report on $M_{\max }$ Workshop, 481 pp., available at http://www.nam.nl/feiten-en-cijfers/onderzoeksrapporten .html (last accessed March 2017).

U.S. Nuclear Regulatory Commission (USNRC) (2012). Practical implementation guidelines for SSHAC Level 3 and 4 hazard studies, NUREG-2117 Revision 1, U.S. Nuclear Regulatory Commission, Office of Nuclear Regulatory Research, Washington, D.C.

van Eck, T., F. Goutbeek, H. Haak, and B. Dost (2006). Seismic hazard due to small-magnitude, shallow-source induced earthquakes in The Netherlands, Eng. Geol. 87, 105-121.

Zöller, G., and M. Holschneider (2014). Induced seismicity: What is the size of the largest expected earthquake? Bull. Seismol. Soc. Am. 104, no. 6, 3153-3158

Zöller, G., and M. Holschneider (2016). The maximum possible and the maximum expected earthquake magnitude for production-induced earthquakes at the gas field in Groningen, The Netherlands, Bull. Seismol. Soc. Am. 106, no. 6, 2917-2921, doi: 10.1785/0120160220.

Civil and Environmental Engineering

Imperial College London

South Kensington

London SW7 2AZ, United Kingdom

j.bommer@imperial.ac.uk

(J.J.B.)

Nederlandse Aardolie Maatschappij B.V. (NAM)

Schepersmaat 2

9405 TA Assen, The Netherlands

Jan.Van-Elk@shell.com

(J.v.)

Manuscript received 7 February 2017; Published Online 18 April 2017 